
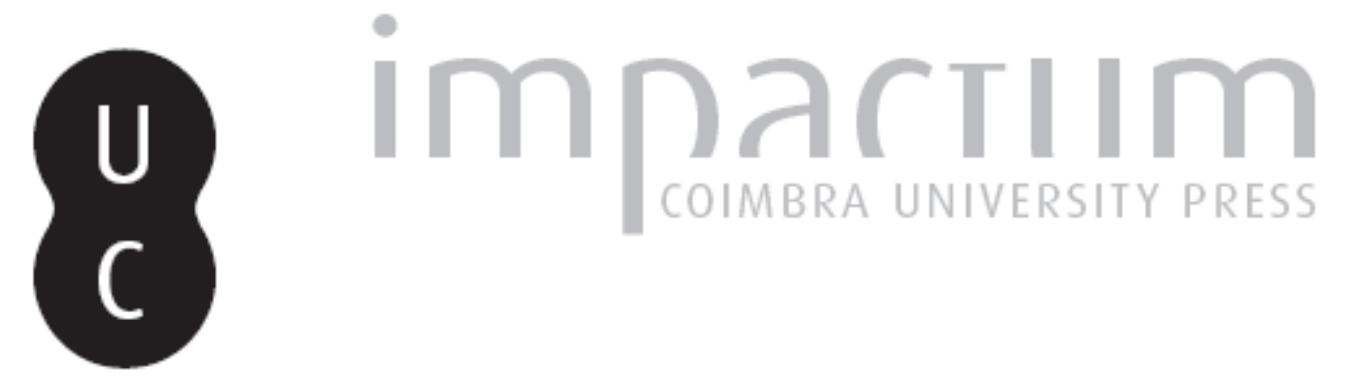

\title{
Christiane Desroches-Noblecourt in Memoriam
}

\section{Autor(es): $\quad$ Araújo, Luís Manuel}

Publicado por: Centro de História da Universidade de Lisboa

URL persistente:

URI:http://hdl.handle.net/10316.2/23646

DOI:

DOI:http://dx.doi.org/10.14195/0871-9527_21_14

Accessed : $\quad$ 26-Apr-2023 13:07:45

A navegação consulta e descarregamento dos títulos inseridos nas Bibliotecas Digitais UC Digitalis, UC Pombalina e UC Impactum, pressupõem a aceitação plena e sem reservas dos Termos e Condições de Uso destas Bibliotecas Digitais, disponíveis em https://digitalis.uc.pt/pt-pt/termos.

Conforme exposto nos referidos Termos e Condições de Uso, o descarregamento de títulos de acesso restrito requer uma licença válida de autorização devendo o utilizador aceder ao(s) documento(s) a partir de um endereço de IP da instituição detentora da supramencionada licença.

Ao utilizador é apenas permitido o descarregamento para uso pessoal, pelo que o emprego do(s) título(s) descarregado(s) para outro fim, designadamente comercial, carece de autorização do respetivo autor ou editor da obra.

Na medida em que todas as obras da UC Digitalis se encontram protegidas pelo Código do Direito de Autor e Direitos Conexos e demais legislação aplicável, toda a cópia, parcial ou total, deste documento, nos casos em que é legalmente admitida, deverá conter ou fazer-se acompanhar por este aviso.

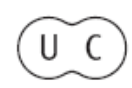



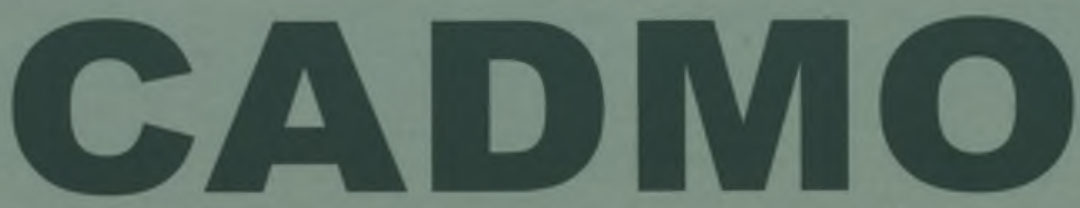

Revista de História Antiga

\author{
Centro de História \\ da Universidade de Lisboa
}

\title{
21
}

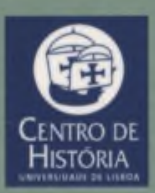

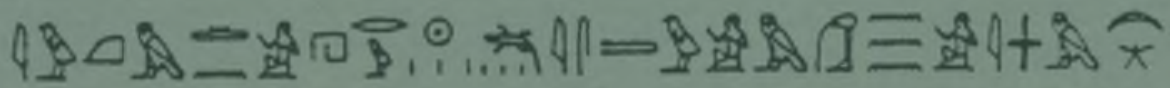

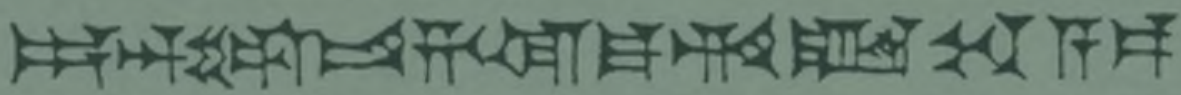

MHNIN AEI $\Delta \mathrm{E} \Theta \mathrm{EA}$ ПH$\Lambda \mathrm{HIA} \triangle \mathrm{E} \Omega$ 


\section{CHRISTIANE DESROCHES-NOBLECOURT}

\section{IN MEMORIAM}

Faleceu no dia 23 de Junho de 2011, em Sézanne (Marne), a egiptóloga francesa Christiane Desroches-Noblecourt, com 97 anos, quase alcançando os provetos limites de outras notáveis e centenárias senhoras da egiptologia como Rosalind Moss (1890-1990) e Margaret Murray (1863-1963).

Christiane Desroches-Noblecourt nasceu em 17 de Novembro de 1913 em Paris, tendo beneficiado do rico ambiente cultural de sua casa. O seu pai era licenciado em Letras e a mãe em Estudos Clássicos, e providenciaram-Ihe uma esmerada educação. Tinha apenas 9 anos quando ficou deslumbrada com a descoberta do rico túmulo de Tutankhamon (1922), e desde então foi robustecendo o seu entusiasmo pelo antigo Egito com as reiteradas visitas ao Museu do Louvre e na contemplação do obelisco de Ramsés II na Praça da Concórdia, sobre o qual dirá mais tarde: “J'aimais les hiéroglyphes gravés sur les quatre faces de granit rose et les petits oiseaux qui sont dessus que je trouvais très amusants. Chaque fois que je découvrais des images de l'Égypte ancienne, je tombais en arrêt devant toutes ces merveilles car tout ce qui touchait à l'Égypte m'attirait."

Estudou na Sorbonne e formou-se em Egiptologia na prestigiada École Pratique des Hautes Études, tendo pouco depois dado entrada no Departamento de Antiguidades Egípcias do Museu do Louvre, onde permaneceu durante cinquenta anos. A primeira das suas centenas de conferências foi proferida no Museu do Louvre em 1932, e o tema proposto foi "Le Trésor de Toutankhamon", tinha então a jovem Christiane 19 anos. O agrado foi geral, em especial do seu professor de Egiptologia Étienne Drioton, um dos grandes egiptólogos da altura e conservador no Museu do Louvre.

Em 1937 teve a primeira oportunidade de concretizar e realizar na prática em trabalhos arqueológicos no Egito a boa formação teórica 
com que estava habilitada, e desde então as suas viagens ao país do Nilo tornaram-se frequentes, interrompidas entretando pela Segunda Guerra Mundial. Foi uma resistente contra a ocupação nazi da França (1940-1944), e um dos seus grandes méritos foi ter posto a salvo em vários locais afastados de Paris diversas obras de arte egípcia de elevado valor. Depois da guerra passou a viajar quase todos os anos para o Egito, escavando em centenas de sítios históricos.

Os seus conhecimentos, aliados ao seu entusiasmo e à simpatia granjearam-Ihe amigos influentes que foram de grande utilidade para a concretização de vários projetos no domínio egiptológico. Foi o caso de René Maheu, delegado da Unesco nas Nações Unidas, em Nova lorque, e depois diretor-geral da Unesco, a quem fez sentir a urgente necessidade de salvar os monumentos egípcios da Núbia que iriam ficar submersos nas águas do lago Nasser com a construção da grande barragem de Assuão. E apesar de na época as relações entre o Egito de Nasser e alguns países europeus (sobretudo a França e a Inglaterra) se terem deteriorado, as conversações com o ministro da Cultura egípcio, Saroïte Okacha, e com o governo do Sudão mantiveram-se e conduziram em 1960 à criação de um comité internacional, sob a égide da Unesco, para o salvamento dos mais importantes vestígios egípcios e núbios a sul de Assuão. Os seus apelos, que contaram com o apoio dos presidentes do Egito e da França, Gamal Abdel Nasser e Charles de Gaule, foram importantes para a obtenção de vultuosos financiamentos e contributos técnicos gerados pela solidária participação de cinquenta países numa ação de grande alcance cultural (e da qual Portugal esteve ausente).

Christiane Desroches-Noblecourt, para quem a nossa civilização ocidental era mais de raiz egípcio-cristã que judaico-cristã, procurou com notável esforço divulgar a civilização do antigo Egito entre o público em geral, para além dos seus contributos no domínio científico da egiptologia. Na sequência do seu grande empenhamento na campanha núbia fundou o Centre de Documentation et d'Études sur l'Art et la Civilisation de l'Ancienne Égypte (C. D. E. A. E), que apoiou documentalmente e cientificamente o projeto internacional.

Dois momentos altos na vida da notável egiptóloga foram as exposições que por sua decisiva ação se organizaram em Paris sobre Tutankhamon (1967) e Ramsés II (1976). Mais uma vez beneficiou de apoios importantes, a começar pelos presidentes Nasser e de Gaule, e ainda do decisivo empenho do ministro francês da Cultura André Malraux e do seu congénere egípcio Saroïte Okacha. A exposição sobre Tutankhamon, no Museu do Louvre, foi visitada por mais de 1 milhão de pessoas, e o 
mesmo sucedeu com Ramsés II, tendo esta ocasião sido aproveitada para realizar um tratamento específico anti-fúngico na múmia do famoso faraó, que viajou de avião desde o Cairo até Paris para ser observada em França.

A sua bibliografia é extensa, com muitos artigos publicados em revistas científicas e de divulgação, sendo de destacar os seguintes livros (alguns deles com várias edições): Le Style Égyptien (1946, depois reeditado e premiado pela Académie des Inscriptions et Belles-lettres), La Religion Égyptienne (1947), L'Art Égyptien (1962), L'Extraordinaire Aventure Amarnienne (1960), Temples de Nubie: Des Tresors Menacés (1961), Toutankhamon, Vie et Mort d'un Pharaon (1963, traduzido em mais de vinte países e premiado pela Académie Française), Le Grand Pharaon Ramsès II et son Temps (1985), La Femme aux Temps des Pharaons (1986), La Grande Nubiade ou le Parcours d'une Égyptologue (1992), Amours et Fureurs de la Lontaine (1995), Ramsés II, la Véritable Histoire (1997), Philae, le Domaine d'Isis (1997), L'Égypte Vue d'en Haut (1998), Le Secret des Temples de la Nubie (1999), La Reine Misterieuse: Hatchepsout (2002), Losrque la Nature Parlait aux Égyptiens (2003), Soux les Regards des Dieux. Les Quatre Vérités d'une Grande Égyptologue (2003), Symboles de l'Égypte, em colaboração com Daniel Elouard (2004), Le Fabuleux Héritage de l'Égypte (2004) e Le Secret des Découvertes (2006). Colaborou em várias obras coletivas, merecendo destaque a sua participação na série Les Pharaons (três volumes), dirigida por Jean Leclant (1978-1980).

Em 1980 comemoraram-se em Paris os cem anos da criação do Institut Français d'Archéologie Orientale (IFAO) com a exposição "Cent ans de fouilles françaises en Égypte", e o evento assinalou um dos últimos atos oficiais de Christiane Desroches-Noblecourt, que dois anos depois deixou as suas funções no Museu do Louvre por ter atingido o limite de idade, ficando como "conservadora honorária". Mais tempo então the ficou para as suas atividades preferidas de escritora e de conferencista e ainda de arqueóloga, levando a cabo profícuos trabalhos de prospeção e de conservação no Vale das Rainhas, em Lucsor Ocidental. Tal como noutros projetos, neste beneficiou de apoio financeiro pela credibilidade do seu trabalho no projeto "Rénovation de la Vallée des Reines", o sítio onde anos antes ela mesmo tinha descoberto o túmulo da rainha Tuia, esposa de Seti I e mãe de Ramsés II.

Foi a primeira mulher a integrar o Institut Français d'Archéologie Orientale (IFAO) e a receber a medalha de ouro do Centre National de la Recherche Scientifique (CNRS), tendo ainda recebido a medalha de 
prata da Unesco, e também uma das raras mulheres distinguidas com a Grã-Cruz da Legião de Honra.

O presidente Nicolas Sarkozy elogiou muito justamente o longo percurso de Christiane Desroches-Noblecourt ao serviço da ciência egiptológica considerando-a como uma «digna herdeira de Jean-François Champollion", salientando a sua entrega ao trabalho museológico e arqueológico com convicção e energia ao serviço de uma causa universal: o salvamento dos templos da Núbia. Para os egiptólogos, a partida do seu ka rumo ao Belo Ocidente marca o final de uma vida terrena dedicada com grande entusiasmo à egiptologia - mas a sua imagem fica também ligada ao nosso país pela valiosa colaboração que prestou na Fundação Calouste Gulbenkian, nomeadamente com os primeiros estudos da colecção egípcia do Museu Calouste Gulbenkian em 1962. Ficará certamente inesquecível, para aqueles que a puderam escutar, a sua conferência sobre a mulher no antigo Egito por ocasião da reconstituição fotográfica em tamanho natural do túmulo da rainha Nefertari, com o apoio técnico da Kodak, que em 1979, e sob a sua coordenação científica, a Fundação Calouste Gulbenkian levou a efeito.

Luís Manuel de Araújo 